\title{
PROFESSIONAL ABILITY TO RECOGNIZE EMOTIONS FROM PHOTOGRAPHS AND ALTERATIONS OF PERSONALITY TRAITS AMONG SECURITY OFFICERS WITH DIFFERENT LENGTH OF WORK EXPERIENCE
}

\author{
Ludmila Kalinnikova $^{1,2}$, Jelena Shaplavska ${ }^{1}$, Aleksey Zavodilov ${ }^{2}$ \\ ${ }^{1}$ Baltic International Academy, ${ }^{2,}$ Psy Technology" LLC \\ kalin.1@inbox.lv, lena.sapl@inbox.lv, aleksejs_zavodilovs@inbox.lv
}

\begin{abstract}
The main purpose of the activities of security service employees is to ensure security and the rule of law. Therefore, one of their professional requirements is the ability to identify elements of nonverbal behaviour that indicate a potential threat to public safety. Paying attention to face expressions can be a basis for potentially threatening intentions recognition. It has been proved that the ability to recognize emotions can be evolved by professional experience related to profiling as well as positive interpersonal communication shaping attitude towards people. In the professional field being studied, there is a contradiction between the requirements assigned to security staff and peculiarities of their professional activities that adversely affect certain characteristics of a person. The study provides a theoretical analysis of contemporary understanding of emotions recognition from photographs as well as of the professional activities impact on altering personality traits. It also provides an empirical exploration of links between the ability to recognize emotions from photographs and such personality characteristics as hostility and trust in people among security officers with different length of work experience. The study revealed that with the increase in time of being employed in a security service, the employees demonstrate tendencies to have increased suspiciousness, nihilism and hostility towards others and reduced ability to recognize face expressions.
\end{abstract}

Keywords: security service, trust in people, hostility, facial expressions.

\section{Introduction}

The relevance of this study is highlighted by insufficient scientific development of psychological aspects of security activities related to safety and the rule of law. The problem of professional requirements impact on manifestations of personality traits of security service employees has also been under-examined.

In the field of professional activity being studied, there is a contradiction between the professional requirements faced by security service employees and the specifics of their professional activities that negatively affect certain personality characteristics. One of the abovementioned professional requirements is the ability to identify signs of nonverbal behaviour that can suggest potential threat to the safety of others. Among the basic skills of this express diagnostics is the ability to recognize an emotional state of a potentially dangerous subject being observed by facial expression as well as to identify the fact that they try to control their mimic message [1]. The current study is based on P.Ekman and his colleagues research. S.Tomkins and McClain [2] revealed that facial expressions correlate with different emotional states. According to P.Ekman [3], facial mimic messages are universal regardless cultural and ethnic identity. Since one of the tasks of security service employees is observing behaviours, among their professionally important qualifications is the ability to evaluate the consistency of emotions manifested by micro expressions, postures, gestures, words and intonations, which allows to notice signs of unusual behaviour. As indicated by P.Ekman [4], facial micro expressions can reveal which emotion a person intentionally hides or tries to suppress. This statement is based on experimental data, which show that facial micro expressions can be understood if an observer has certain skills of monitoring facial micro expressions in a specific context that is related to professional experience.

A number of authors $[1 ; 5]$ mention that professional faults can be a result of social perception distortion and/or of misrepresentations of certain requirements of a profession. For example, among security service employees, visual perception distortion whilst observing a subject can be caused by a tunnel vision (a subjective choice of elements for observation) [1] or by personal exasperation of an employee manifested in hostility and animosity towards others and suspiciousness [4]. T.Smith [6] and other authors $[7 ; 8]$ define hostility as a significant cause of distortion in interpersonal perception. The study of Weiss and Cropanzano [9] revealed that high levels of hostility significantly correlate with a large number of errors in emotions recognition from facial expression. P.Ekman and colleagues [3-4] highlight that in many cases professional requirements oblige employees to constantly control their 
emotions. As a result, repressed or incompletely expressed emotions can contribute to an increase in hostility as a personality trait. The dynamics of hostility during professional activity is theoretically explained by the Affective Events Theory (AET) [10], where hostility is defined as a multidimensional concept treated both as a disposition of an individual and as a condition.

In this study, hostility was examined in a social context. Such hostility components as cynicism and mistrust of people [6] are manifested in a tendency to expect aggressive actions or intentions from other people and perceive any uncertain situation as an unequivocally threatening, whilst attributing hostility to others. As a result, an erroneous interpretation of non-verbal behavior can occur. The phenomenon of trust in people as an opposite to mistrust [11] is considered as being a category of the concept of trust or as a basic interpersonal predisposition [12]. From this perspective, trust is understood as certain expectations on behalf of a person that others' behaviour is associated with honesty, predictability and appropriateness. It has been noted that trust is especially important in a situation of uncertainty and absence of control over circumstances. This understanding of trust is particularly relevant when considering interpersonal interaction in situations of conflict as well as when helping victims of terrorist attacks or other types of disasters. Here, the emphasis is put on the degree of trust of an affected person to an individual providing help since trust serves as a factor diminishing perceptions of a risk and responding to uncertainty.

In Sztompk's model, the concept of trust is associated with the notion of risk. The author mentions that trust is "a bet on unpredictable actions of others that can arise in future" [13]. P.Sztompk points out [13] that trust leads to ignoring the risk of unforeseen actions arousal on behalf of another person. The repetition of situations when relationship based on trust led to errors and violation of interaction strengthens mistrust towards people. On the other hand, it is noted that a person with a high level of trust towards others never has enough reliable information about the situation and behaviors of others, which makes this situation uncertain. Trust in this case is associated with the risk of erroneous actions on the part of a person who has higher degrees of trust. The concept draws attention to the influence of social functions on the manifestation of trust. It is pointed out that in some professions, including security organisations, mistrust is unilaterally sanctioned.

The construct of trust is a multidimensional concept that has been explained by different theoretical positions, however, a number of authors indicate that there is no an unambiguous understanding [14]; the dynamics of trust in the context of professional activities related to security and safety have not been studied either.

In this study, the concept of trust in people is interpreted as a basic interpersonal predisposition [12], based, to a large extent, on professional experience and professional information about nonverbal behaviour that can indicate a potential threat to the safety of others. In a situation of uncertainty, trust in people allows to reduce risks, including professional errors [14].

Research questions and the aim of this study are theoretically based on conceptual models of cognitive theories $[6 ; 12]$, explaining social perception distortions and erroneous interpretations of behaviour by hostility manifestations.

The study provides a theoretical analysis of contemporary understanding of the emotions recognition from photographs as well as of the professional activities impact on altering personality traits. It also provides an empirical examination of links between the ability to recognize emotions and personality traits among security officers with different length of work experience.

\section{Research questions}

1. Whether there is a link between trust in people, hostility and the ability to recognize emotions from photographs?

2. Whether there is a difference in trust in people, hostility and the ability to recognize emotions from photographs among security service employees with different length of work experience?

\section{Materials and methods}

\section{Study participants}

60 security service employees voluntarily participated in the study, all men - the sample is homogeneous. The participants were divided into two groups: participants with one to three years of 
professional experience $(N=30$; age: $\bar{X}=24.9 ; s=2.5)$ and participants with three to five years of professional experience $(N=30$; age: $\bar{X}=30.97 ; s=3.1)$. Sample type - a convenience sample.

Methods of the study

- Faith in People Scale (M.Rosenberg, 1957) [12; 15].

- Cook-Medley Hostility Scale (1954) [15; 16].

- Facial Micro Expressions Test (P.Ekman) [4; 15].

In the current study, only two subsets of the Cook-Medley Hostility Scale were used: Hostile Affect and Cynicism. The Aggressive Responding subset was not considered as all participants demonstrated low levels of aggressive responding.

\section{Results and discussion}

\section{Descriptive Statistics}

Descriptive statistics revealed the non-normal distribution of the empirical data; therefore, the non-parametrical criteria were implemented for further analysis. The link between trust in people, hostility and the ability to recognize emotions from photographs was analysed by the Spearman rank correlation coefficient. To investigate the differences in trust in people, hostility, and the ability to recognize emotions from photographs among security officers with different length of work experience the non-parametric Mann-Whitney $U$ test was implemented. Data processing was run by SPSS 20.0 computer software. The mathematical apparatus of the study was chosen to answer the research questions defined above.

\section{Correlation analysis}

The analysis revealed a weak positive correlation between trust in people and the ability to recognize emotions from photographs among security service employees $(r=0.375, p \leq 0.01)$.

A weak negative correlation was identified between hostility and the ability to recognize emotions from photographs among security service employees $(r=-0.259, p \leq 0.05)$.

The correlation diagrams illustrate that among security service employees upon the work experience increase there is an increase in suspicion $(r=0.810, p \leq 0.001$; Fig. 1$)$, in the tendency towards nihilism and hostile attitude towards others $(r=0.747, p \leq 0.001$; Fig. 2$)$; a decrease in the ability to recognize faces was also identified $(r=-0.402, p \leq 0.001$; Fig. 3$)$.

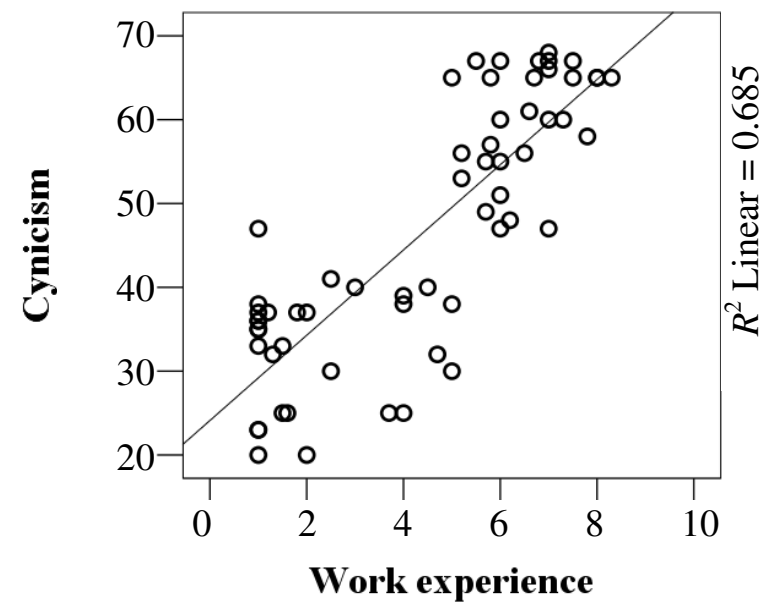

Fig. 1. Correlation diagram "Cynicism - Work Experience"

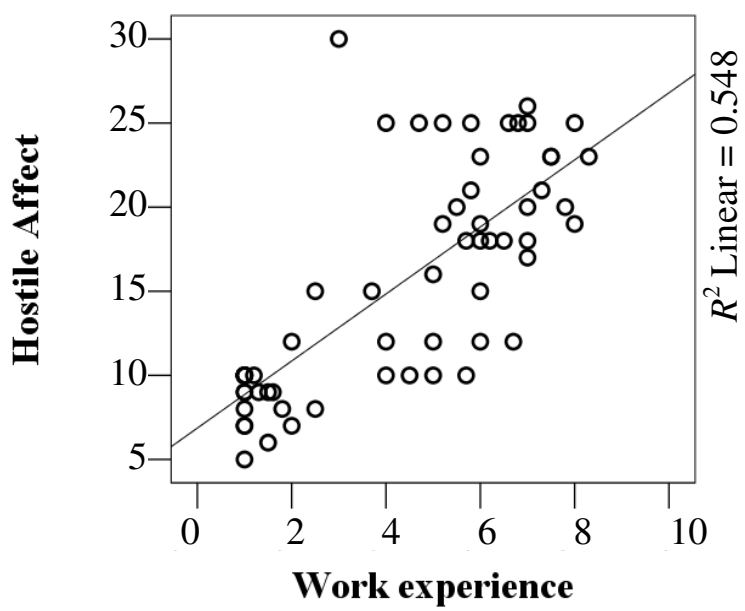

Fig. 2. Correlation diagram "Hostile Affect- Work Experience" 


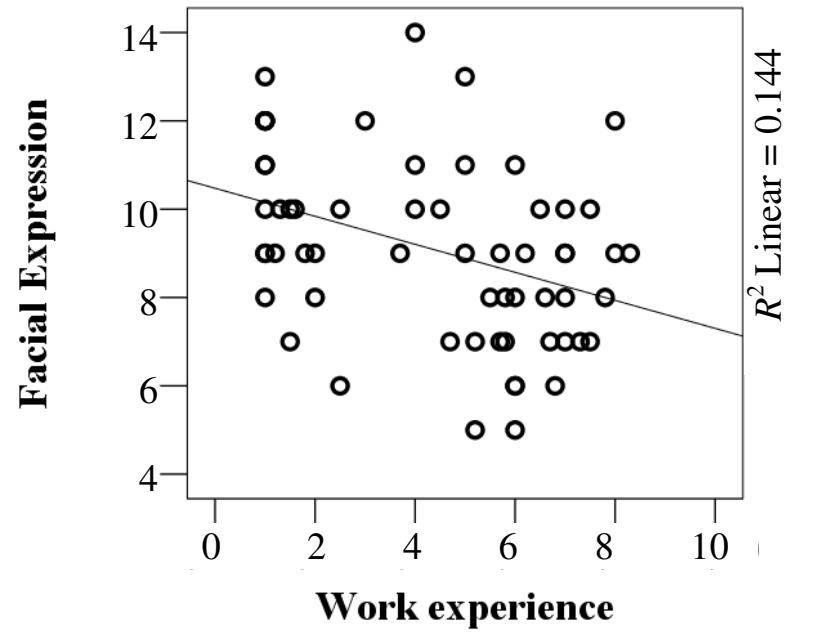

Fig. 3. Correlation diagram "Facial Expression - Work Experience"

\section{Analysis of differences}

According to the analysis, trust in people, hostility and the ability to recognize emotions from photographs differ among security service officers with different length of work experience. The differences are revealed across all variables at the maximal level of significance (Table 1):

Table 1

Test Statistics ${ }^{\mathrm{a}}$, Comparison of variables

\begin{tabular}{|c|c|c|c|c|}
\hline & $\begin{array}{c}\text { Faith in } \\
\text { People }\end{array}$ & Cynicism & $\begin{array}{c}\text { Hostile } \\
\text { Affect }\end{array}$ & $\begin{array}{c}\text { Facial } \\
\text { Expression }\end{array}$ \\
\hline Mann-Whitney U & 90.000 & 1.000 & 99.500 & 183.500 \\
\hline Asymp. Sig. (2-tailed) & .000 & .000 & .000 & .000 \\
\hline
\end{tabular}

a. Grouping Variable: Work Experience

- Security service employees with 1-3 years of experience have more trust in people in comparison to security service officers with 3-5 years of experience $(p \leq 0.001)$;

- Hostility is higher among security service employees with 3-5 years of experience $(p \leq 0.001)$;

- The ability to recognize emotions from photographs is higher among security service employees with 1-3 years of experience ( $p \leq 0.001$ );

- Suspiciousness is higher among security service employees with 3-5 years of experience in comparison to the respondents with less professional experience $(p \leq 0.001)$.

\section{Discussion}

As a result of this study, a theoretical analysis of contemporary understanding of the emotions recognition from photographs as well as of the professional activities impact on altering personality traits was run. An analysis of the links between the ability to recognize emotions and personal characteristics of security service employees with different length of work experience was also conducted.

Cognitive conceptual models of hostility, cynicism [6], and trust in people [12] were chosen as a theoretical basis of the study. These theoretical positions as well as the results of P. Ekman's studies [3-5] provided grounds of understanding of how professional experience and specificity of professional activities are related to increasing hostility among security services employees and their ability to recognize hidden emotions by facial micro expressions.

The duration of being involved in a professional activity and its influence on changes in psychological qualities of an employee is regarded as one of the professional deformation factors. It 
was revealed that professional deformation can be manifested in changing patterns of social perception, character features, preferred ways of communication and behaviour [17].

As a result of the current study, a statistically significant positive correlation was revealed between trust in people and the ability to recognize emotions from photographs among security service employees.

The revealed negative correlation of hostility and the ability to recognize emotions from photographs among security service employees has confirmed S.Enikolopov's et al. [18] findings. In their study, hostility was defined as the most powerful factor altering individual and social perception. It was revealed that upon increase of the length of professional experience among security service employees, such features as suspiciousness, nihilistic tendencies and hostility towards others increase, whilst, the ability to recognize faces decreases. Similar results were obtained in O.Abakumov's [19] study investigating private security companies' employees. After 3 years of service, the employees demonstrated professional deformation signs manifested in increasing suspicion, ambitiousness and feeling of superiority over others.

At the same time, the current study revealed that security service employees, whose professional work experience does not exceed three years, demonstrate more trust in people and more ability to recognize emotions from photographs. With increase of the professional experience length, hostility and suspicion also increase. The explanation of the results is ambiguous. On the one hand, it can be assumed that as the length of professional experience among security service officers increases, there is also an increase in circumspection and cautiousness in making decisions. Employees with less work experience do not yet have complete confidence in controlling the situation, so they are required to trust in other people. On the other hand, due to professional demands and higher level of competence, the cognitive bias towards other people can be a cause for misinterpreting emotional reactions of others as more threatening as well as a result of the hostility development as a manifestation of professional stress. The obtained results also revealed professional deformation signs, thus, confirming the findings of O.Abakumov [19].

\section{Conclusions}

1. With increase of the professional experience length among security service employees, suspiciousness, tendencies to nihilism and hostility towards others increases, whilst, the ability to recognize emotions by facial micro expressions decreases.

2. Hostility as a basic interpersonal feature can lead to distortions in social perception and errors in facial micro expressions recognition; mistrust and suspicion (cynicism) as hostility components can be manifested in anticipation of aggressive actions or intentions on behalf of others.

3. The study revealed signs of general professional deformation (social perception distortion) as well as features specific to the activities of security services (cynicism and hostile, sceptical attitude to people).

4. Weak relationships between the variables revealed in the study can be explained by heterogeneity of the sample in terms of the length of professional experience.

5. Further extended study on the impact of security service peculiarities on employees' professionally important qualities deterioration and individual profile changes is required.

\section{References}

1. Stolyarenko A., Eriashvili N. Psychological characteristics of identifying potentially dangerous persons using observations of external features. In: Bulletin of the Moscow University of the Interior Ministry, vol.11, 2014, pp. 255-258. (In Russian).

2. Tomkins S.S., McCarter R. What and where are the primary affects? Some evidence for a theory. Perceptual and Motor Skills, vol.18, 1964, pp. 119-158.

3. Ekman P., Friesen W. Unmasking the Face. Cambridge, MA: Malor Books, 2003, pp.50-51.

4. Ekman P. Lying and Deception. In: Memory for Everyday and Emotional Events. Hillsdale, N.J.: Lawrence Erlbaum Associates, 1997, pp. 333-347.

5. Ekman P. Emotions Revealed. Times Books. Henry Holt and Company LLC. New York, 2003, pp. 64-65; 279-281; 297-314. (In Russian). 
6. Smith T.W., Mc Gonigle M.A., Benjamin L.S. Sibling interaction self-regulation, and cynical hostility in adult male twins. Journal of Behavioral Medicine, vol. 21, 1998, pp. 337-349

7. Timothy W.S. Concepts and methods in the study of anger, hostility, and health. Journal "Angel, hostility, and the heart", 1994, p.26.

8. Guyll M., Madon S. Trait hostility: The breadth and specificity of schema effects. Personality and Individual Differences, vol.34, 2003, pp. 681-693.

9. Howard M.W., Cropanzano R. Affective Events Theory: A Theoretical Discussion of the Structure, Cause and Consequences of Affective Experiences at Work. Research in Organizational Behavior, vol.18, 1996, pp. 1-74

10. Kevin T., Larkin R., Martin S., McClain E. Cynical Hostility and the Accuracy of Decoding Facial Expressions of Emotions. Journal of Behaviolal Medicine, vol. 25, 2002, pp. 285-292.

11. Lewicki R., Mcallister D., Bies R. Trust and Distrust: New relationships and realities. Academy of Management Review, vol. 23, 1998, pp. 439-458.

12. Rosenberg M. Organizations and values. Glencoe, IL: Free Press, 1957, pp. 25-35. This scale was published in: Robinson J.P., Shaver P.R., Wrightsman L.S. Measures of personality and social psychological attitudes. San Diego: Academic Press, 1991, pp. 404-406.

13. Sztompka P. Trust: a sociological theory. Cambridge University Press, 1999, 214 p.

14. Castaldo S. Meanings of Trust: Meta-Analysis of Trust Definitions: Paper presented at Second Euram Conference. Stockholm, 2002, p. 57.

15. Labunskaya V., Mendzcherickaya J., Breus E. Psychology of Impeded Communication. Moscow: ACADEMA, 2001, pp. 104-108. (In Russian).

16. Cook W., Medley D. Propose hostility and pharisaic-virtue scales for the MMPI. Journal of Applied Psychology, 1954, vol. 38, pp. 414-418.

17. Polykova O. Category and Structure of Professional Deformation. National Psychological Journal, 2014, vol. 1, pp. 57-64. (In Russian).

18. Enikolopov S., Kuznecova J., Chudova N. Aggressiveness and inability to understand other people's emotions. In: http//psymagazine.moscow/articles/280216. (In Russian).

19. Abakumov O. The influence of professional activities on personal features of employees of private security companies, 2005. In: www.dissertcat.com. (In Russian). 